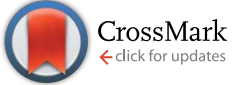

Cite this: Chem. Sci., 2016, 7, 3614

\title{
Conjugated polymer-enhanced enantioselectivity in fluorescent sensing $\dagger$
}

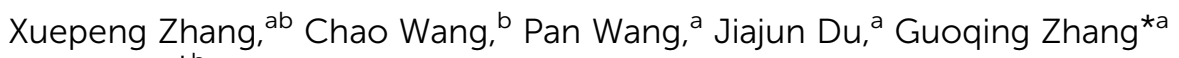 \\ and Lin $\mathrm{Pu}^{* \mathrm{~b}}$
}

A new strategy to use conjugated polymers to conduct fluorescent enhancement sensing has been developed. Chiral 1,1'-bi-2-naphthol-based binding sites are linked by $p$-phenylene units to construct a conjugated polymer whose fluorescence is quenched by the aldehyde groups introduced at each binding site. Interaction of this polymer with chiral amino alcohols in the presence of $\mathrm{Zn}(॥)$ leads to highly enantioselective fluorescent enhancement. It is found that the chiral conjugated polymer shows greatly enhanced enantioselectivity over the corresponding small molecular sensor under the same conditions. This work provides the first example that a conjugated polymer is used to greatly increase the enantioselectivity of a small molecular sensor in chiral recognition. Simultaneous determination of the concentration and enantiomeric composition of chiral substrates by a fluorescent measurement has been achieved by combining the polymer with salicylaldehyde in the assay.

Received 19th January 2016

DOI: $10.1039 / \mathrm{c} 6 \mathrm{sc00266h}$

www.rsc.org/chemicalscience

this conjugated polymer bind with a specific substrate, the

\section{Introduction}

Conjugated polymers such as polyacetylenes, poly( $p$-phenylene) $\mathrm{s}$, polythiophenes, poly( $p$-phenylenevinylene)s and polyanilines have been extensively studied in the past four decades. ${ }^{1}$ These research efforts have uncovered many applications for conjugated polymers in areas such as organic conductors, electroluminescent devices, sensors, nonlinear optical devices as well as high energy density batteries, etc. ${ }^{1,2}$ For example, in 1995, Zhou and Swager demonstrated that when a conjugated polymer, a poly(phenyleneethynylene), was equipped with binding sites for a fluorescent quenching molecule, it showed greatly increased fluorescent quenching over the use of a small molecule sensor. ${ }^{2 a}$ As shown in Fig. 1a, when the quencher binds with a single binding site of the conjugated polymer, it can quench the fluorescence of the entire polymer chain due to energy migration along the conjugated polymer chain. In this way, the conjugated polymer can be used to detect the quenching molecule at much lower concentrations than a small molecular sensor can do. A strongly fluorescent conjugated polymer as shown in Fig. 1a is thus converted to a weakly fluorescent or non-fluorescent polymer.

An opposite scenario is shown in Fig. 1b where a non-fluorescent conjugated polymer is used. When the binding sites of

${ }^{a}$ Hefei National Laboratory for Physical Sciences at the Microscale, University of Science and Technology of China, 96 Jinzhai Road, Hefei, Anhui, 230026, China. E-mail: gzhang@ustc.edu.cn

${ }^{b}$ Department of Chemistry, University of Virginia, Charlottesville, Virginia 229044319, USA. E-mail: lp6n@virginia.edu

$\dagger$ Electronic supplementary information (ESI) available. See DOI: $10.1039 / \mathrm{c} 6 \mathrm{sc} 00266 \mathrm{~h}$ fluorescence of the conjugated polymer can be turned on, thus giving a fluorescent enhancement sensor. That is, the binding sites of the polymer quench the fluorescence but the substrate binding inhibits the fluorescent quenching and enhances the fluorescence. In this situation, the sensitivity of such a conjugated polymer-based fluorescent enhancement sensor should be lower than the corresponding small molecular sensor, since only after all the fluorescent quenching binding sites are bonded to the substrate, can the fluorescence of the conjugated polymer chain be turned on. Even if there is only one binding site on the conjugated polymer chain not complexed with the substrate, the fluorescence of the entire polymer can still be quenched by this binding site due to the energy migration along the conjugated polymer chain.

That is, the energy migration along a conjugated polymer chain is good for the development of a more sensitive

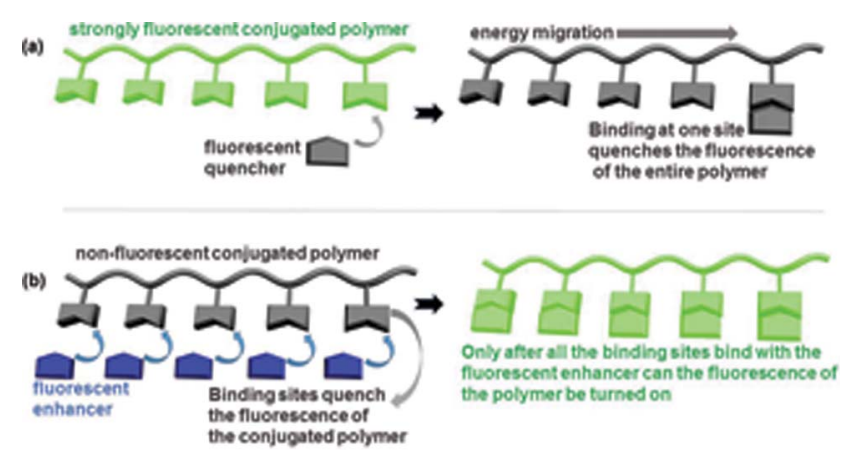

Fig. 1 Using conjugated polymers as fluorescent sensors. 
fluorescent quenching sensor as shown in Fig. 1a but not good for the development of a fluorescent enhancement sensor as shown in Fig. 1b. Therefore, such a conjugated polymer design has not been utilized for the development of fluorescent enhancement sensors due to the expected reduced sensitivity.

In the past two decades, there has been significant progress in the study of the enantioselective fluorescent recognition of chiral organic compounds aiming at development of a fast analytical tool for chiral assay. ${ }^{3}$ A number of small moleculebased sensors have been obtained to carry out highly sensitive as well as enantioselective fluorescent detection of organic compounds such as $\alpha$-hydroxycarboxylic acids, amines, amino alcohols and amino acids. ${ }^{3,4}$ However, much less work has been conducted on the development of chiral polymer-based fluorescent sensors. ${ }^{5}$

We propose to use the energy migration in the conjugated polymer as described in Fig. 1b to enhance the enantioselectivity in chiral recognition, a previously unexplored strategy. Chirality will be incorporated into the conjugated polymer of Fig. $1 \mathrm{~b}$ to conduct the enantioselective fluorescence enhancement recognition of chiral molecules. This chiral conjugated polymer will be equipped with molecular binding sites that can quench the fluorescence of the polymer chain, similar to that depicted in Fig. 1b, and can be used to interact with the enantiomers of a chiral molecule, which turn on the fluorescence of the polymer upon binding at the binding sites. It is our hypothesis that the energy migration along such a chiral conjugated polymer chain could lead to enhancement of the enantioselectivity in comparison to a corresponding small molecule sensor. Since only until all of the binding sites of the polymer bind with the substrates can there be major fluorescent enhancement, the fluorescent detection requires a cumulative action of the enantiomers of the substrate along the polymer chain. This should lead to the desired increased enantioselectivity as illustrated below.

When the binding of one binding site of the polymer shown in Fig. 1 b with the $R$ and $S$ enantiomer of a chiral molecule leads to an enantioselective response of $I_{R} / I_{S} \neq 1$, the overall enantioselectivity of the polymer chain in the fluorescent enhancement could be represented as $\left(I_{R} / I_{S}\right)^{n}$ where $n$ is the number of the binding sites in the polymer chain. For example, if this enantioselective fluorescent response is due to a difference in the equilibrium constant $K_{R} / K_{S}$ for the reaction of the two enantiomers of the substrate with each binding site, the overall equilibrium constant ratio should be $\left(K_{R} / K_{S}\right)^{n}$ for the polymer because of the cumulative effect. Thus, when at one binding site there is only a very low $5 \%$ enantioselective response (that is, $I_{R} /$ $I_{S}=1.05$ ), for a polymer chain of 30 binding sites it could generate up to $1.05^{30}>4$ times stronger response toward the $R$ substrate than the $S$ substrate! Thus, a poorly enantioselective small molecular fluorescent sensor could be converted to a highly enantioselective polymeric sensor by attaching the small molecule-based binding site into a conjugated polymer chain. The increased enantioselective fluorescent response could well compensate the potentially reduced sensitivity since in chiral recognition it is more challenging and highly desirable to achieve high enantioselectivity. In this paper, we present the first example of this strategy in which a conjugated polymer is used to greatly increase the enantioselectivity of a small molecular sensor in chiral recognition.

\section{Results and discussion}

Previously, we have synthesized a class of main-chain chiral conjugated polymers such as $(S)-\mathbf{1}$ and $(S)-2$ by incorporating chiral binaphthyl units into the conjugated polymer chains and have investigated their various applications. ${ }^{6-8}$ For example, we found that the strong fluorescence of $(S)-2$ can be quenched more efficiently by amines than that of the small 1,1'-bi-2naphthol (BINOL) molecule, ${ }^{5 \boldsymbol{a}}$ a possible consequence of an efficient energy migration along the chiral conjugated polymer chain as described in Fig. 1a.

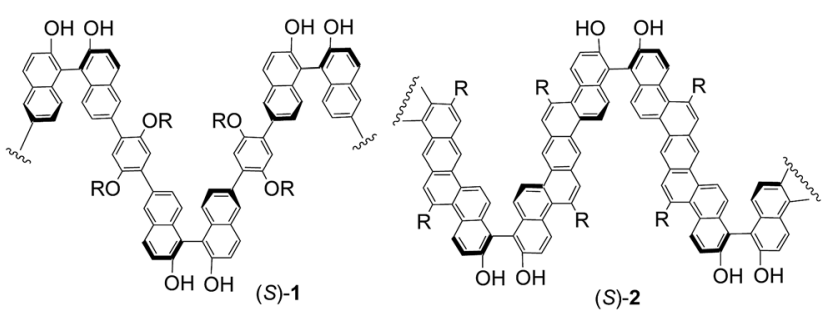

Although BINOL is strongly fluorescent, introduction of $3,3^{\prime}$ diformyl groups into $(S)$-BINOL has effectively quenched the fluorescence in the resulting dialdehyde molecule $(S)$-3. This fluorescent quenching is attributed to the intramolecular hydrogen bonding between the hydroxyl groups and the adjacent carbonyl oxygen which could undergo an excited-state proton transfer process to quench the fluorescence. We recently found that the fluorescence of $(S)-3$ can be turned on upon reaction with functional chiral amines in the presence of $\mathrm{Zn}$ (II) to generate the corresponding imine-Zn(II) complexes. ${ }^{9}$

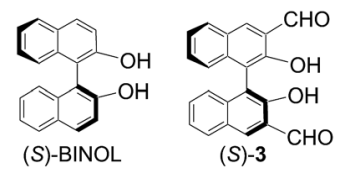

We have incorporated the aldehyde groups into the BINOL polymer $(S)$-1 and synthesized a new chiral conjugated polymer as shown in Scheme 1. Following the literature procedure, $(S)$ BINOL was converted to the MOM-protected dialdehyde. ${ }^{\mathbf{1 0 , 1 1}}$ Treatment of this compound with bromine in methylene chloride followed by aqueous work-up gave the 6,6'-brominated product $(S)$-4. In this step, the two MOM protecting groups were also removed due to the formation of $\mathrm{HBr}$ during the bromination. The Suzuki coupling of $(S)-4$ with the diboronic acid 5 in the presence of $\mathrm{Pd}\left(\mathrm{PPh}_{3}\right)_{4}$ gave polymer $(S)-6$ as a yellow solid. The molecular weight of the polymer was determined to be $M_{\mathrm{n}}$ $=89000$ (PDI = 1.35) by using gel permeation chromatography relative to the poly(ethylene glycol) standards.

Polymer $(S)-6$ gives a well-resolved ${ }^{1} \mathrm{H}$ NMR spectrum in $\mathrm{CDCl}_{3}$ solution as shown in Fig. S1, $\dagger$ demonstrating a welldefined and sterically regular structure of high molecular weight. The signal at $\delta 10.61(\mathrm{~s}, 2 \mathrm{H})$ is attributed to the $\mathrm{OH}$ 


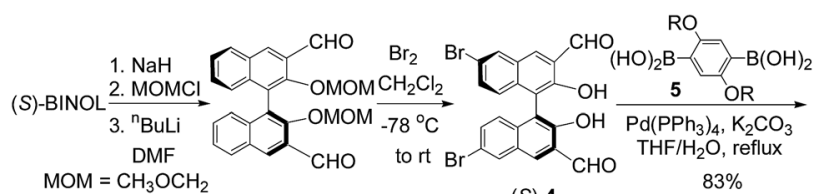
(S)-4

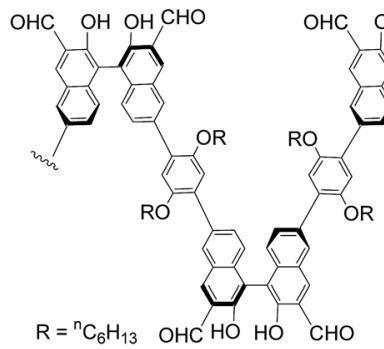

$\mathrm{OHC} \mathrm{OH} \mathrm{OH} \mathrm{CHO}$

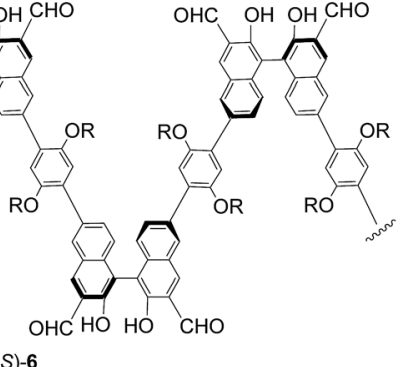

(S)-6

Scheme 1 Synthesis of polymer (S)-6.

groups since addition of $\mathrm{D}_{2} \mathrm{O}$ led to its diminishing (Fig. S20†). This greatly down-field-shifted $\mathrm{OH}$ signal indicates an intramolecular hydrogen bonding between the hydroxyl proton and the aldehyde oxygen. The signal at $\delta 10.21(\mathrm{~s}, 2 \mathrm{H})$ is attributed to the CHO groups. These signals are very close to those of the monomeric compound $(R)-3 .{ }^{10}$ The specific optical rotation of $(S)-6$ is found to be $[\alpha]_{\mathrm{D}}=-29.7\left(c=0.106, \mathrm{CHCl}_{3}\right)$.

The enantiomer of polymer $(S)-6$ was also prepared by starting with $(R)$-BINOL which gave polymer $(R)$-6. GPC analysis of $(R)$-6 showed $M_{\mathrm{n}}=34000(\mathrm{PDI}=1.71)$. The specific optical rotation of $(R)-6$ was found to be $[\alpha]_{\mathrm{D}}=34.0\left(c=0.112, \mathrm{CHCl}_{3}\right)$, the opposite sign of that of $(S)$-6.

Since polymer $(S)-6$ is soluble in common organic solvents such as $\mathrm{CH}_{2} \mathrm{Cl}_{2}$, THF and chloroform, but insoluble in methanol and water, we investigated the fluorescent responses of this main -chain chiral conjugated polymer as well as the monomeric compound $(S)-3$ toward chiral amino alcohols in $\mathrm{CH}_{2} \mathrm{Cl}_{2}$ solution. We first studied the interaction of $(S)-3$ with $(R)$ - and (S)-leucinol (7) in the presence of $\mathrm{Zn}(\mathrm{II})$. In $\mathrm{CH}_{2} \mathrm{Cl}_{2}$ solution, $(S)$-3 gives very weak fluorescence. When a solution of $(S)-3$ in $\mathrm{CH}_{2} \mathrm{Cl}_{2}\left(5.0 \times 10^{-5} \mathrm{M}\right)$ was treated with $\mathrm{Zn}(\mathrm{OAc})_{2}(2$ equiv.), there was little change in its fluorescence. When this $(S)-3+\mathrm{Zn}$ (II) (2 equiv.) solution was treated with $(R)$ - or $(S)-7$, the fluorescence at $\lambda=515 \mathrm{~nm}$ was turned on, but the enantioselectivity was low with the enantioselective fluorescent enhancement $(\mathrm{ef})=1.3\left[\mathrm{ef}=\left(I_{R}-I_{0}\right) /\left(I_{S}-I_{0}\right) \cdot I_{0}\right.$ : the fluorescent intensity of $(S)-3+\mathrm{Zn}$ (II) in the absence of $7 . I_{R}$ and $I_{S}$ : fluorescence intensity in the presence of $(R)$ - and $(S)$-7 respectively] when the aminol alcohol concentration is $5.0 \times 10^{-5} \mathrm{M}$ (Fig. S2 $†$ ). ${ }^{9}$

We then studied the fluorescent response of polymer $(S)-6$ toward the amino alcohol under the same conditions as the use of $(S)$-3. In $\mathrm{CH}_{2} \mathrm{Cl}_{2}$ solution, similar to $(S)$-3, $(S)$-6 showed little fluorescence. That is, the aldehyde function groups have effectively quenched the fluorescence of the BINOL-based conjugated polymer $(S)$-1. When a solution of $(S)-6$ in $\mathrm{CH}_{2} \mathrm{Cl}_{2}(5.0 \times$ $10^{-5} \mathrm{M}$ ) was treated with $\mathrm{Zn}(\mathrm{OAc})_{2}$ (2 equiv.), there was only a slight increase in its fluorescence. However, when this $(S)-\mathbf{6}+$ $\mathrm{Zn}(\mathrm{II})$ (2 equiv.) solution was treated with $(R)$ - or $(S)-7$, the

fluorescence was greatly enhanced (Fig. 2 and S3†). As shown in Fig. 2a, when the solution of $(S)-6+\mathrm{Zn}$ (II) was treated with 1 equiv. $(R)$ - and $(S)-7$, large fluorescence enhancements were observed at $\lambda=535 \mathrm{~nm}$ with the $R$ amino alcohol increasing the fluorescence much more than the $S$ enantiomer with ef $=3.5$. When the concentration of the leucinol enantiomers was increased from $1.0 \times 10^{-5} \mathrm{M}$ to $1.0 \times 10^{-4} \mathrm{M}$, the fluorescence of $(S)-6+\mathrm{Zn}$ (II) continuously increased (Fig. 2b). For a concentration of the amino alcohol of $>1.0 \times 10^{-4} \mathrm{M}$, the fluorescence enhancement reached saturation. Thus, the detection range of the polymer toward the amino alcohol is around $\sim 1.0 \times 10^{-5} \mathrm{M}$ to $\sim 1.0 \times 10^{-4} \mathrm{M}$.

We examined the use of $(R)-6$, the enantiomer of the polymer $(S)$-6, in combination with $\mathrm{Zn}$ (II) for the fluorescent recognition of $(R)$ - and $(S)-7$ under the same conditions. Mirror-image fluorescent responses as $(S)-6$ were observed which confirmed the observed enantioselective recognition (Fig. $S 4 \dagger$ ).

The observations in Fig. 2 and $\mathrm{S} 2 \uparrow$ demonstrate for the first time that a conjugated polymer can be used to greatly enhance the enantioselectivity of a small molecular fluorescent sensor. In addition, the originally assumed reduction in fluorescent sensitivity from the small molecule to the polymer is not observed. We attribute this to the introduction of the conjugated phenylene linkers in the polymer which might have greatly increased the inherent fluorescent intensity of the small BINOL molecule before quenching by the aldehyde groups. Thus, using the main chain chiral conjugated polymer (S)-6 has allowed us to harvest the greatly enhanced enantioselectivity without sacrificing the fluorescent sensitivity.

We then studied the effect of the enantiomeric composition of the amino alcohol on the fluorescence of $(S)-6+\mathrm{Zn}$ (II) at various amino alcohol concentrations. While maintaining the concentrations of $(S)-6$ and $\mathrm{Zn}$ (II) at $5.0 \times 10^{-5} \mathrm{M}$ and $1.0 \times 10^{-4}$ $\mathrm{M}$, respectively, we selected five total concentrations of leucinol $\left(2.0 \times 10^{-5}, 4.0 \times 10^{-5}, 6.0 \times 10^{-5}, 8.0 \times 10^{-5}\right.$, and $1.0 \times 10^{-4}$ $\mathrm{M})$ and at each concentration we selected eleven percentages of $(R)$-leucinol $(0 \%, 10 \%, 20 \%, 30 \%, 40 \%, 50 \%, 60 \%, 70 \%, 80 \%$, $90 \%$ and $100 \%$ ). The fluorescent intensity at each total concentration increased when the content of the $R$ amino alcohol increased while the emission wavelength remained almost the same and centered at $\sim 535 \mathrm{~nm}$ at each enantiomeric composition. At each total concentration of the amino alcohol, an approximate linear relationship was obtained between the

(a)

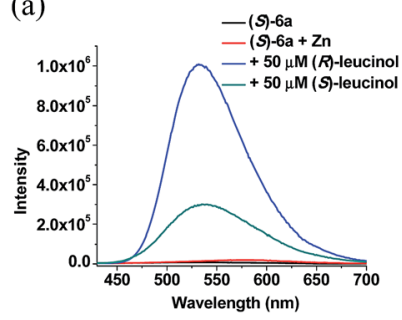

Fig. 2 Fluorescent spectra of $(S)-6\left(5.0 \times 10^{-5} \mathrm{M}\right)+\mathrm{Zn}(\mathrm{II})\left(1.0 \times 10^{-4} \mathrm{M}\right)$ in $\mathrm{CH}_{2} \mathrm{Cl}_{2}$ with 1 equiv. of $(R)$ - and (S)-leucinol (a). Fluorescent intensities at $\lambda=535 \mathrm{~nm}$ versus leucinol concentrations (error bars are from three independent measurements) (b). ( $\lambda_{\mathrm{ex}}=355 \mathrm{~nm}$, slit: $3 / 3 \mathrm{~nm}$ ). 
fluorescent intensity at $535 \mathrm{~nm}, I_{535}$, and the percentages of $(R)$ leucinol (Fig. 3). Thus, the polymer can be utilized to determine the enantiomeric composition of leucinol at a given concentration.

We recently reported that the fluorescence enhancement of the achiral molecule salicylaldehyde in combination with $\mathrm{Zn}$ (II) in the presence of amines can be used to determine the amine concentration. ${ }^{\mathbf{1 2}}$ Since the fluorescent enhancement of salicylaldehyde $+\mathrm{Zn}$ (II) in the presence of amines occurs at $\lambda \approx 447$ $\mathrm{nm}$ which is significantly shorter than the emission wavelength of the polymer $(S)-6+\mathrm{Zn}$ (II) upon interaction with the amino alcohol, it is proposed to use the fluorescence of the mixture of salicylaldehyde $+(S)-6+\mathrm{Zn}$ (II) to report the concentration of the substrate at the short wavelength and the enantiomeric composition at the long wavelength.

$$
\mathrm{OH}_{\mathrm{OH}}^{\mathrm{CHO}} \text { salicylaldehyde }
$$

We prepared a $1: 2$ mixture of $(S)-6$ and salicylaldehyde in $\mathrm{CH}_{2} \mathrm{Cl}_{2}$ at concentrations of $5.0 \times 10^{-5} \mathrm{M}$ and $1.0 \times 10^{-4} \mathrm{M}$, respectively, which showed only weak fluorescence upon excitation at $355 \mathrm{~nm}$. Addition of 2 equiv. of $\mathrm{Zn}(\mathrm{OAc})_{2}\left(3.0 \times 10^{-4} \mathrm{M}\right)$ to this solution resulted in only very slight fluorescence enhancement. The fluorescent response of the $(S)-6+$ salicylaldehyde $+\mathrm{Zn}$ (II) mixture toward $(R)$ - and $(S)-7$ was investigated. As shown in Fig. 4a and b, the amino alcohol enantiomers caused large fluorescence enhancement at two emission wavelengths of $\lambda_{1}=\sim 430 \mathrm{~nm}$ and $\lambda_{2}=\sim 530 \mathrm{~nm}$. We attribute the fluorescent enhancement at $\lambda_{1}$ to the reaction of salicylaldehyde with the amino alcohol and $\mathrm{Zn}$ (II) to form a salicylimine-Zn(II) complexes, and that at $\lambda_{2}$ to the reaction of $(S)-6$ to form similar complexes of more extended conjugation. Both intensities at $\lambda_{1}$ and $\lambda_{2}$ increased with increasing concentration of $(R)-7$ and the intensities at $\lambda_{2}$ at all the studied concentrations are generally higher than those at $\lambda_{1}$. In the presence of $(S)-7$, the major fluorescent enhancement was observed at the short wavelength $\lambda_{1}$ with lower intensities at $\lambda_{2}$. Fig. $4 \mathrm{c}$ and d display the effects of the concentration of the leucinol enantiomers on the fluorescent intensities at $\lambda_{1}$ and $\lambda_{2}$. As shown in Fig. 4c, both enantiomers of the leucinol give similar fluorescent enhancement at $\lambda_{1}$. Fig. $4 \mathrm{~d}$ shows good enantioselective fluorescent responses at $\lambda_{2}$.

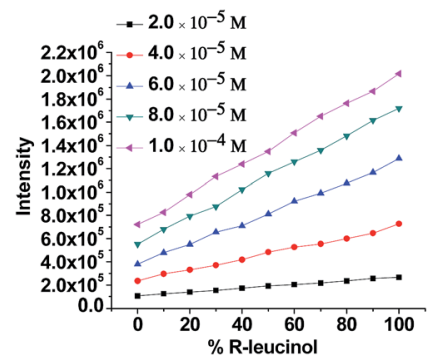

Fig. 3 Fluorescent response of (S)-6 (5.0 $\left.\times 10^{-5} \mathrm{M}\right)+\mathrm{Zn}(॥)\left(1.0 \times 10^{-4}\right.$ M) in $\mathrm{CH}_{2} \mathrm{Cl}_{2}$ at $\lambda_{\mathrm{em}}=535 \mathrm{~nm}$ toward leucinol at various total concentrations with varying percentages of $(R)$-leucinol $\left(\lambda_{\text {ex }}=355 \mathrm{~nm}\right.$, slit: $3 / 3 \mathrm{~nm}$ ) (a)

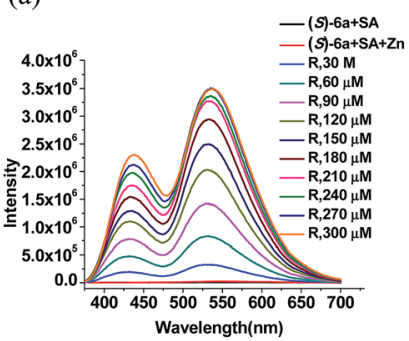

(c)

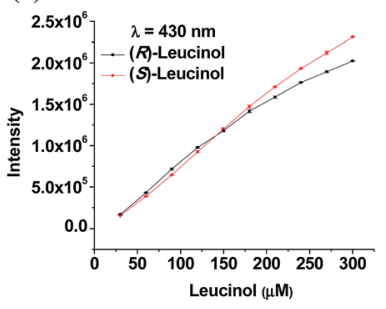

(b)

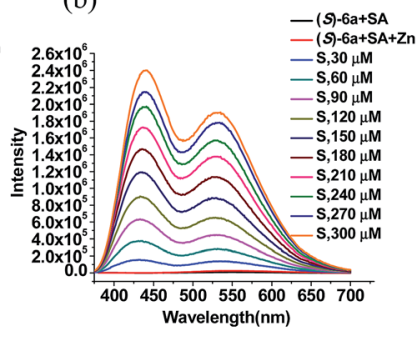

(d)

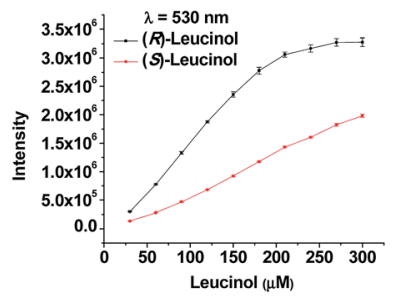

Fig. 4 Fluorescent response of (S)-6 + salicylaldehyde $(1: 2$, total concentration: $1.5 \times 10^{-4} \mathrm{M}$ in $\left.\mathrm{CH}_{2} \mathrm{Cl}_{2}\right)+\mathrm{Zn}^{\prime \prime}\left(3.0 \times 10^{-4} \mathrm{M}\right)$ towards $(R)$ - and $(S)-7\left(\lambda_{\text {ex }}=355 \mathrm{~nm}\right.$, slits: $\left.3 / 3 \mathrm{~nm}\right)$.

We then studied the fluorescent response of the $(S)-6+$ salicylaldehyde $+\mathrm{Zn}^{\text {II }}$ sensor system toward leucinol at varying enantiomeric compositions at selected concentrations and the results are summarized in Fig. 5 and S5. $\dagger$ It was observed that at each total concentration of leucinol, the intensity at $\lambda_{1}$ decreased slightly while the intensity at $\lambda_{2}$ increased significantly as the composition of the $R$ amino alcohol increased. Fig. 5a shows that the fluorescent intensity of the sensor at $\lambda_{1}$ is predominately determined by the total concentration of the two enantiomers and is slightly influenced by the enantiomeric composition. Fig. 5b shows that as the composition of $(R)-7$ increases, the emission at $\lambda_{2}$ increases. Both the concentration

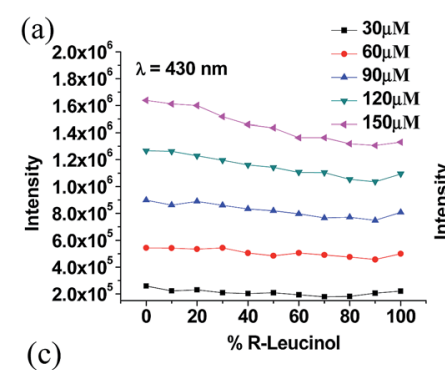

(c)

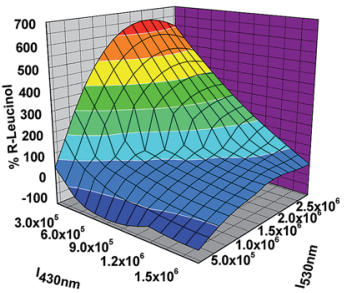

(b)

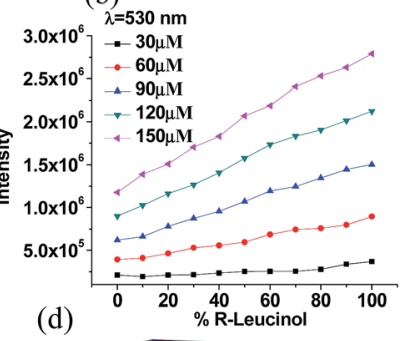

(d)

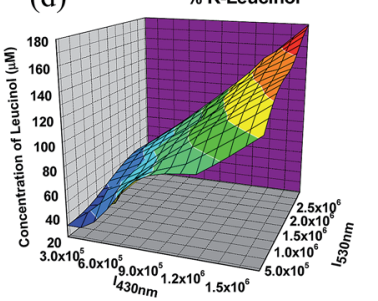

Fig. 5 Fluorescent response of $(S)-6+$ salicylaldehyde $(1: 2$, total concentration: $1.5 \times 10^{-4} \mathrm{M}$ in $\left.\mathrm{CH}_{2} \mathrm{Cl}_{2}\right)+\mathrm{Zn}^{\prime \prime}\left(3.0 \times 10^{-4} \mathrm{M}\right)$ vs. the enantiomeric purity of 7 at various concentrations at $\lambda_{1}(a)$ and $\lambda_{2}(b)$, and the 3D plots (c and d) ( $\lambda_{\mathrm{ex}}=355 \mathrm{~nm}$, slits: $3 / 3 \mathrm{~nm}$ ). 
and enantiomeric composition of the amino alcohol strongly influence the fluorescent intensity at $\lambda_{2}$. We have obtained a 3D graph by plotting the fluorescent intensities at $\lambda_{1}$ and $\lambda_{2}$ against the enantiomeric composition of leucinol at various total concentrations (Fig. 5c). Fig. 5d is another 3D graph obtained by plotting the fluorescent intensities at $\lambda_{1}$ and $\lambda_{2}$ against the total concentration of the leucinol enantiomers. This plot corrects the small effect of the enantiomeric purity on the fluorescent intensity at $\lambda_{1}$ while being used to determine the total concentration of leucinol. Thus, using Fig. $5 \mathrm{c}$ and d allows simultaneous determination of both the concentration and enantiomeric composition of leucinol by one fluorescent measurement. The use of the enantiomeric polymer $(R)-6$ in combination with $\mathrm{Zn}$ (II) and salicylaldehyde for the recognition of leucinol was also studied. As shown in Fig. S6, $\uparrow$ an expected mirror image relation with the responses of $(S)-6$ was observed.

We further investigated the fluorescent response of $(S)-6+$ $\mathrm{Zn}$ (II) toward a variety of amino alcohols as listed in Fig. 6. In addition to the amino alcohol 7 described above, good enantioselective fluorescent responses were also observed for the interaction of $(S)-6\left(5.0 \times 10^{-5} \mathrm{M}\right)+\mathrm{Zn}$ (II) $\left(1.0 \times 10^{-4} \mathrm{M}\right)$ with the amino alcohols 8-11 in $\mathrm{CH}_{2} \mathrm{Cl}_{2}$ in certain concentration ranges (Fig. S7-S10 $\dagger$ ). In each case, the $R$ enantiomer causes greater fluorescent enhancement than the $S$ enantiomer. Table 1 gives the ef data for the interactions of the sensor with the enantiomers of the amino alcohols at two concentrations. It shows that the amino alcohol $\mathbf{9}$ with the most sterically bulky substituent adjacent to the chiral amine center gives the highest ef value, that is the highest enantioselectivity, and the amino alcohol $\mathbf{1 1}$ with the least steric bulkiness gives the lowest ef value. The order of the size of the substituents on the chiral amine carbons of the amino alcohols is $\mathbf{1 1}<\mathbf{1 0}<\mathbf{8 - 7}<\mathbf{9}$ which is the same as the order of their enantioselectivity in the fluorescent responses. Thus, the size of the substituents on the chiral amine carbon center is important for the enantioselective fluorescent response.

We also studied the use of the monomeric compound $(S)-3$ to interact with various amino alcohols under the same conditions. As shown in Table 2 and Fig. S11-S15, $\uparrow$ the fluorescent enantioselectivity of $(S)-3$ toward these amino alcohols in $\mathrm{CH}_{2} \mathrm{Cl}_{2}$ are low and none of the ef values are greater than 1.5.

Comparison of the data in Tables 1 and 2 shows clearly the large enhancement in enantioselectivity from the small molecular sensor to the chiral conjugated polymer in the recognition of various chiral amino alcohols except for compound $\mathbf{1 1}$ which contains the smallest substituent adjacent to the chiral center. For example, in the recognition of the amino alcohol 9, up to five-fold increase in the ef value has been achieved.

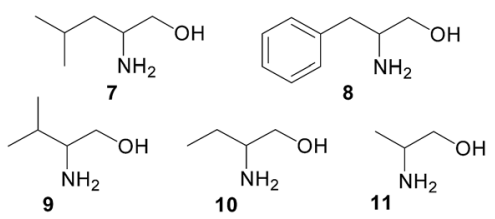

Fig. 6 Chiral amino alcohols investigated.
Table 1 The ef data for the fluorescent responses of $(S)-6\left(5.0 \times 10^{-5}\right.$ $\mathrm{M})+\mathrm{Zn}(\mathrm{II})\left(1.0 \times 10^{-4} \mathrm{M}\right)$ in $\mathrm{CH}_{2} \mathrm{Cl}_{2}$ toward various amino alcohols

\begin{tabular}{lcc}
\hline & \multicolumn{2}{c}{ ef at two amino alcohol concentrations } \\
\cline { 2 - 3 } Amino alcohol & $5.0 \times 10^{-5} \mathrm{M}$ & $1.0 \times 10^{-4} \mathrm{M}$ \\
\hline 7 & 3.5 & 2.9 \\
$\mathbf{8}$ & 3.6 & 3.1 \\
$\mathbf{9}$ & 5.3 & 5.4 \\
$\mathbf{1 0}$ & 3.2 & 2.0 \\
& 1.8 & 1.5
\end{tabular}

\section{Experimental}

\section{General data}

NMR spectra were recorded on a Bruker-600 MHz spectrometer. Chemical shifts for ${ }^{1} \mathrm{H}$ NMR spectra were reported in parts per million relative to a singlet at $7.26 \mathrm{ppm}$ for the residual chloroform in deuterated chloroform. Chemical shifts for ${ }^{13} \mathrm{C}$ NMR were reported relative to the centerline of a triplet at $77.16 \mathrm{ppm}$ for deuterated chloroform. Molecular weights and polydispersity indices were determined by GPC in THF $\left(20^{\circ} \mathrm{C}\right.$; flow

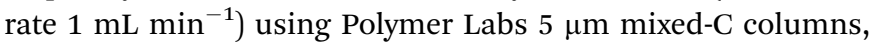
a Hewlett-Packard 1100 instrument equipped with a laser refractometer LR40 (Viscotek), and Viscotek software (TriSEC GPC Version 3.0, Viscotek Corp.). Poly(ethylene glycol) standards (Polymer Laboratories) were used for molecular weight calibration. Samples were dissolved in THF $(0.4 \% \mathrm{w} / \mathrm{v})$ and passed through a $0.2 \mu \mathrm{m}$ filter before injection. Steady-state fluorescence emission spectra were recorded on a Horiba FluoroMax-4 spectrofluorometer. High-resolution mass spectra were obtained from the University of Illinois at Urbana-Champaign (UIUC) Mass Spectrometry Facility. UV-Vis spectra were produced from a Hewlett-Packard 8452A diode-array spectrophotometer. Unless otherwise noted, materials were obtained from commercial suppliers and were used without further purification. All of the solvents were either HPLC or spectroscopic grade in the optical spectroscopic studies.

Synthesis of $(S)-6,6^{\prime}$-dibromo-2,2'-dihydroxy-[1,1'-binaphthalene]-3,3'-dicarbaldehyde, $\quad(S)$-4. $\quad(S)-2,2^{\prime}$-Bis(methoxymethoxy)-[1,1'-binaphthalene]-3,3'-dicarbaldehyde (1.39 g, 3.2 $\mathrm{mmol}$ ) was dissolved in $5 \mathrm{~mL}$ methylene chloride, followed by three freeze-vacuum-thaw cycles. Under $\mathrm{N}_{2}$, bromine $(660 \mu \mathrm{L}$,

Table 2 The ef data for the fluorescent responses of (S) $-3\left(5.0 \times 10^{-5}\right.$ $\mathrm{M})+\mathrm{Zn}(\mathrm{II})\left(1.0 \times 10^{-4} \mathrm{M}\right)$ in $\mathrm{CH}_{2} \mathrm{Cl}_{2}$ toward various amino alcohols

\begin{tabular}{lcc}
\hline & \multicolumn{2}{c}{ ef at two amino alcohol concentrations } \\
\cline { 2 - 3 } Amino alcohol & $5.0 \times 10^{-5} \mathrm{M}$ & $1.0 \times 10^{-4} \mathrm{M}$ \\
\hline 7 & 1.3 & 1.2 \\
$\mathbf{8}$ & 1.5 & 1.3 \\
$\mathbf{9}$ & 1.3 & 1.1 \\
$\mathbf{1 0}$ & 1.3 & 1.4 \\
$\mathbf{1 1}$ & 1.5 & 1.5
\end{tabular}


$12.8 \mathrm{mmol}$ ) was added dropwise to this solution at $-78{ }^{\circ} \mathrm{C}$ and then the mixture was warmed to room temperature and stirred for $12 \mathrm{~h}$. The reaction was then quenched by $\mathrm{Na}_{2} \mathrm{~S}_{2} \mathrm{O}_{3}(\mathrm{aq})$ and the organic layer was washed with brine. After removal of methylene chloride under reduced pressure, the residue was eluted with methylene chloride/ $n$-hexane $(1: 4)$ to give the product $(S)-4$ as a yellow solid in $85 \%$ yield. ${ }^{1} \mathrm{H}$ NMR $(600 \mathrm{MHz}$, $\left.\mathrm{CDCl}_{3}\right) \delta 10.60(\mathrm{~s}, 2 \mathrm{H}), 10.05(\mathrm{~s}, 2 \mathrm{H}), 8.26(\mathrm{~s}, 2 \mathrm{H}), 8.16(\mathrm{~s}, 2 \mathrm{H})$, 7.47 (d, $J=9.1 \mathrm{~Hz}, 2 \mathrm{H}), 7.05$ (d, $J=9.1 \mathrm{~Hz}, 2 \mathrm{H}) .{ }^{13} \mathrm{C}$ NMR (151 $\mathrm{MHz}, \mathrm{CDCl}_{3}$ ) $\delta 196.72(\mathrm{~s}), 154.14(\mathrm{~s}), 137.43(\mathrm{~s}), 135.82(\mathrm{~s}), 134.02$ $(\mathrm{s}), 131.78(\mathrm{~s}), 128.76(\mathrm{~s}), 126.66(\mathrm{~s}), 122.78(\mathrm{~s}), 118.50(\mathrm{~s}), 116.58$ (s). HRMS (ES+): $m / z[\mathrm{M}+\mathrm{H}]^{+}$calc. for $\mathrm{C}_{22} \mathrm{H}_{13} \mathrm{Br}_{2} \mathrm{O}_{4} 500.9160$, found $500.9155 ; \mathrm{mp}>260{ }^{\circ} \mathrm{C}$.

Synthesis of $(R)-6,6^{\prime}$-dibromo-2,2'-dihydroxy-[1,1'-binaphthalene]-3, $\mathbf{3}^{\prime}$-dicarbaldehyde, $(\boldsymbol{R})$-4. The same procedure as the synthesis of $(S)-4$ except that $(R)-2,2^{\prime}$-bis(methoxymethoxy)-[1,1'binaphthalene]-3,3'-dicarbaldehyde was used as the starting material. Yield 79\%. ${ }^{1} \mathrm{H}$ NMR (600 $\left.\mathrm{MHz}, \mathrm{CDCl}_{3}\right) \delta 10.60(\mathrm{~s}, 2 \mathrm{H})$, 10.05 (s, 2H), 8.26 (s, 2H), $8.16(\mathrm{~s}, 2 \mathrm{H}), 7.47$ (d, $J=9.1 \mathrm{~Hz}, 2 \mathrm{H})$, $7.05(\mathrm{~d}, J=9.1 \mathrm{~Hz}, 2 \mathrm{H}) .{ }^{13} \mathrm{C} \mathrm{NMR}\left(151 \mathrm{MHz}, \mathrm{CDCl}_{3}\right) \delta 196.72(\mathrm{~s})$, 154.15 (s), 137.43 (s), 135.82 (s), 134.02 (s), 131.79 (s), 128.76 (s), 126.66 (s), 122.78 (s), 118.50 (s), 116.58 (s). HRMS (ES+): m/z $[\mathrm{M}+\mathrm{H}]^{+}$calc. for $\mathrm{C}_{22} \mathrm{H}_{13} \mathrm{Br}_{2} \mathrm{O}_{4} 500.9160$, found 500.9159; mp > $260{ }^{\circ} \mathrm{C}$.

Preparation of polymer $(S)-6$. Under $\mathrm{N}_{2}$, a mixture of $(S)-4(0.3$ g, $0.6 \mathrm{mmol}$ ), (2,5-bis(hexyloxy)-1,4-phenylene)diboronic acid (5, $0.22 \mathrm{~g}, 0.6 \mathrm{mmol})$ and $\mathrm{Pd}\left(\mathrm{PPh}_{3}\right)_{4}(22 \mathrm{mg}, 60 \mu \mathrm{mol})$ in THF $(3 \mathrm{~mL})$ and $1 \mathrm{M} \mathrm{K}_{2} \mathrm{CO}_{3}(3 \mathrm{~mL})$ was heated at $80{ }^{\circ} \mathrm{C}$ for $80 \mathrm{~h}$. Then $\mathrm{HCl}$ (aq, $1 \mathrm{M}$ ) was added to acidify the reaction mixture and methylene chloride was added to extract. The organic layer was washed with brine, concentrated under reduced pressure and added dropwise to excess methanol to precipitate out the polymer. The precipitation was repeated for three times and the resulting polymer was separated by centrifugation and dried under vacuum to give $(S)-6$ as a yellow powder in $83 \%$ yield. ${ }^{1} \mathrm{H}$ NMR (600 MHz, $\mathrm{CDCl}_{3}$ ) $\delta 10.61(\mathrm{~s}, 2 \mathrm{H}), 10.21$ (s, 2H), 8.38 (s, $2 \mathrm{H}), 8.24(\mathrm{~s}, 2 \mathrm{H}), 7.73(\mathrm{~d}, J=9.1 \mathrm{~Hz}, 2 \mathrm{H}), 7.31(\mathrm{~d}, J=7.9 \mathrm{~Hz}, 2 \mathrm{H})$, 7.08 (d, $J=4.0 \mathrm{~Hz}, 2 \mathrm{H}), 3.94$ (d, $J=5.7 \mathrm{~Hz}, 4 \mathrm{H}), 1.67$ (d, $J=5.5$ $\mathrm{Hz}, 4 \mathrm{H}), 1.55$ (s, 4H), $1.34(\mathrm{~s}, 4 \mathrm{H}), 1.20(\mathrm{~s}, 4 \mathrm{H}), 0.76(\mathrm{~s}, 6 \mathrm{H}) .{ }^{13} \mathrm{C}$ $\mathrm{NMR}\left(\mathrm{CDCl}_{3}, 151 \mathrm{MHz}\right) \delta 196.87,153.94,150.62,138.82,136.63$, $134.74,132.96,130.53$, 130.05, 127.81, 124.58, 122.42, 116.61, $116.15,69.74,31.56,29.43,25.94,22.69,14.07 ;$ GPC $M_{\mathrm{n}}=$ 89000, PDI $=1.35$.

Preparation of polymer $(\boldsymbol{R})-6$. Under $\mathrm{N}_{2}$, a mixture of $(R)-4$ (0.3 g, $0.6 \mathrm{mmol}),(2,5$-bis(hexyloxy)-1,4-phenylene)diboronic acid $(5,0.22 \mathrm{~g}, 0.6 \mathrm{mmol})$ and $\mathrm{Pd}\left(\mathrm{PPh}_{3}\right)_{4}(22 \mathrm{mg}, 60 \mu \mathrm{mol})$ in THF ( $6 \mathrm{~mL})$ and $0.5 \mathrm{M} \mathrm{K}_{2} \mathrm{CO}_{3}(6 \mathrm{~mL})$ was heated at $80^{\circ} \mathrm{C}$ for $63 \mathrm{~h}$. Then $\mathrm{HCl}$ (aq, $1 \mathrm{M}$ ) was added to acidify the reaction mixture and methylene chloride was added to extract. The organic layer was washed with brine, concentrated under reduced pressure and added dropwise to excess methanol to precipitate out the polymer. The precipitation was repeated for three times and the resulting polymer was separated by centrifugation and dried under vacuum to give $(R)-6$ as a yellow powder in $66 \%$ yield. ${ }^{1} \mathrm{H}$ NMR (600 MHz, $\mathrm{CDCl}_{3}$ ) $\delta 10.62(\mathrm{~d}, J=20.1 \mathrm{~Hz}, 2 \mathrm{H}), 10.21$ (s, $2 \mathrm{H}), 8.38(\mathrm{~s}, 2 \mathrm{H}), 8.22(\mathrm{~d}, J=37.8 \mathrm{~Hz}, 2 \mathrm{H}), 7.79-7.66(\mathrm{~m}, 2 \mathrm{H})$, 7.46-7.30 (m, 2H), 7.08 (s, 2H), 4.01-3.86 (m, 4H), 1.74-1.62 (m,
$4 \mathrm{H}), 1.34(\mathrm{~d}, J=6.3 \mathrm{~Hz}, 4 \mathrm{H}), 1.21(\mathrm{~s}, 8 \mathrm{H}), 0.77(\mathrm{~d}, J=6.4 \mathrm{~Hz}, 6 \mathrm{H})$. ${ }^{13} \mathrm{C} \mathrm{NMR}\left(\mathrm{CDCl}_{3}, 151 \mathrm{MHz}\right) \delta 196.86,153.95,150.63,138.80$, 136.63, 135.18, 134.74, 132.95, 130.65, 130.18, 129.76, 128.19, $127.81,124.58,122.42,116.62,116.16,69.75,31.55,29.43$, 25.94, 22.69, 14.07; GPC $M_{\mathrm{n}}=34000$, PDI $=1.71$.

\section{Preparation of samples for fluorescence measurement}

For the interactions between the polymer $+\mathrm{Zn}^{\text {II }}$ sensor systems and the amino alcohols. A $50 \mu \mathrm{M}$ stock solution of a polymer in methylene chloride and $0.1 \mathrm{M}$ stock solution of $\mathrm{Zn}(\mathrm{OAc})_{2} \cdot 2 \mathrm{H}_{2} \mathrm{O}$ in $\mathrm{CH}_{3} \mathrm{OH}$ were freshly prepared for each measurement. They were mixed at the polymer $/ \mathrm{Zn}^{\mathrm{II}}$ molar ratio of $1: 2$ to obtain the polymer $+\mathrm{Zn}^{\mathrm{II}}$ sensor. For the fluorescence enhancement study, the sensor solution was mixed with various equiv. of amino alcohol (5 mM stock solution in methylene chloride) in a $10 \mathrm{~mL}$ volumetric flask. The flask was then sealed with Teflon and agitated on a shaker for $4 \mathrm{~h}$ at room temperature before the fluorescence measurement.

For the interactions between the polymer + salicylaldehyde + $\mathrm{Zn}^{\mathrm{II}}$ sensor systems and the amino alcohols. The same procedure with the polymer $+\mathrm{Zn}^{\mathrm{II}}$ sensor systems was adopted except that polymer + salicyladehyde $(50 \mu \mathrm{M}: 100 \mu \mathrm{M})$ stock solution was used.

\section{Conclusions}

In conclusion, a new strategy to develop conjugated polymerbased fluorescent sensors has been described. We have demonstrated for the first time that a conjugated polymer can be used to greatly enhance the enantioselectivity of a small molecular sensor in the fluorescent recognition of chiral compounds. The fluorescence of a main chain chiral conjugated polyBINOL is quenched by incorporation of aldehyde groups. In the presence of $\mathrm{Zn}(\mathrm{II})$, this polymer shows highly enantioselective fluorescent enhancement toward chiral amino alcohols in $\mathrm{CH}_{2} \mathrm{Cl}_{2}$. Under the same conditions, the corresponding monomeric BINOL compound gave very low enantioselectivity in its fluorescent responses. Simultaneous determination of the concentration and enantiomeric composition of the chiral substrates is also conducted by combining the polymer with salicylaldehyde in the fluorescent measurement.

Besides the enantioselectivity enhancement described in this work, the conjugated polymer-based sensors could also be used to increase the selectivity in the fluorescent discrimination of other competing substrates because it requires a cumulative response of all the fluorescent quenching binding sites on the polymer chain toward a fluorescent enhancement substrate. A small difference at each binding site can be augmented along the polymer chain. The polymer-based enantioselective fluorescent sensors also have other potential advantages when used in high through-put screening of chiral compounds in asymmetric synthesis. For example, they could be used to selectively bind with the chiral product of a reaction mixture which can then be separated from the reaction mixture by filtration, membrane filtration or precipitation/filtration before 
fluorescent measurement. This strategy can minimize the interference of other species on the optical measurement. Polymers can also be used to prepare films and membranes to fabricate optical sensors. Work along these lines will be conducted in our laboratories.

\section{Acknowledgements}

Partial supports of this work from the donors of the Petroleum Research Fund-administered by the American Chemical Society are gratefully acknowledged. GQZ thanks the support of the National Natural Science Foundation of China (21222405) and XPZ thanks the fellowship from China Scholarship Council. We thank Prof. Fraser and Dr Derosa for their assistance on the GPC measurements.

\section{Notes and references}

1 (a) Handbook of Conducting Polymers, ed. T. A. Skotheim, Marcel Dekker, New York, 1986, vol. 1 and 2; (b) J. L. Bredas and R. Silbey, Conjugated Polymers: The Novel Science and Technology of Highly Conducting and Nonlinear Optically Active Materials, Kluwer Academic Publishers, Boston, MA, 1991; (c) Conjugated Conducting Polymers, ed. H. G. Kiess, Springer-Verlag, New York, 1992.

2 Selected references on conjugated polymer-based fluorescent sensors: (a) Q. Zhou and T. M. Swager, J. Am. Chem. Soc., 1995, 117, 7017-7018; (b) D. T. McQuade, A. E. Pullen and T. M. Swager, Chem. Rev., 2000, 100, 25372574; (c) S. W. Thomas, G. D. Joly and T. M. Swager, Chem. Rev., 2007, 107, 1339-1386; (d) H. Jiang, P. Taranekar, J. R. Reynolds and K. S. Schanze, Angew. Chem., Int. Ed., 2009, 48, 4300-4316; (e) H. N. Kim, Z. Q. Guo, W. H. Zhu, J. Yoon and H. Tian, Chem. Soc. Rev., 2011, 40, 79-93; $(f)$ L. H. Feng, C. L. Zhu, H. X. Yuan, L. B. Liu, F. T. Lv and S. Wang, Chem. Soc. Rev., 2013, 42, 6620-6633; $(g)$ C. Gu, N. Huang, J. Gao, F. Xu, Y. H. Xu and D. L. Jiang, Angew. Chem., Int. Ed., 2014, 53, 4850-4855.

3 For reviews on enantioselective fluorescent recognition: (a) L. Pu, Chem. Rev., 2004, 104, 1687-1716; (b) D. Leung, S. O. Kang and E. V. Anslyn, Chem. Soc. Rev., 2012, 41, 448479; (c) A. Accetta, R. Corradini and R. Marchelli, Top.
Curr. Chem., 2011, 300, 175-216; (d) X. Zhang, J. Yin and J. Yoon, Chem. Rev., 2014, 114, 4918-4959.

4 Selected publications: (a) T. D. James, K. R. A. S. Sandanayake and S. Shinkai, Nature, 1995, 374, 345-347; (b) J. Lin, Q.-S. Hu, M. H. Xu and L. Pu, J. Am. Chem. Soc., 2002, 124, 2088-2089; (c) J.-Z. Zhao, T. M. Fyles and T. D. James, Angew. Chem., Int. Ed., 2004, 43, 34613464; (d) L. Zhu and E. V. Anslyn, J. Am. Chem. Soc., 2004, 126, 3676-3677; (e) X. F. Mei and C. Wolf, J. Am. Chem. Soc., 2004, 126, 14736-14737; (f) L. Pu, Acc. Chem. Res., 2012, 45, 150-163.

5 (a) H.-C. Zhang and L. Pu, Macromolecules, 2004, 37, 26952702; (b) S. Vandeleene, M. Verswyvel, T. Verbiest and G. Koeckelberghs, Macromolecules, 2010, 43, 7412; (c) F. Song, G. Wei, L. Wang, J. Jiao, Y. Cheng and C. Zhu, J. Org. Chem., 2012, 77, 4759-4764; (d) J. Hou, F. Song, L. Wang, G. Wei, Y. Cheng and C. Zhu, Macromolecules, 2012, 45, 7835-7842; (e) G. Wei, S. Zhang, C. Dai, Y. Quan, Y. Cheng and C. Zhu, Chem.-Eur. J., 2013, 19, 16066-16071. 6 (a) L. Pu, 1,1'-Binaphthyl-Based Chiral Materials: Our Journey, World Scientific Inc. - Imperial College Press, London, 2010; (b) L. Pu, Chem. Rev., 1998, 98, 2405-2494.

7 Selected papers: (a) W.-S. Huang, Q.-S. Hu, X.-F. Zheng, J. Anderson and L. Pu, J. Am. Chem. Soc., 1997, 119, 43134314; (b) Q.-S. Hu, W.-S. Huang, D. Vitharana, X.-F. Zheng and L. Pu, J. Am. Chem. Soc., 1997, 119, 12454-12464; (c) L. Ma, Q.-S. Hu, D. Vitharana, C. Wu, C. M. S. Kwan and L. Pu, Macromolecules, 1997, 30, 204; (d) H.-B. Yu, Q.-S. Hu and L. Pu, J. Am. Chem. Soc., 2000, 122, 6500-6501.

8 Examples of polybinaphthyls prepared by other laboratories: (a) Y. Liu, S.-W. Zhang, Q. Miao, L.-F. Zheng, L.-L. Zong and Y.-X. Cheng, Macromolecules, 2007, 40, 4839-4847; (b) X. Huang, Y. Xu, Q. Miao, L. Zong, H. Hu and Y. Cheng, Polymer, 2009, 50, 2793-2805.

9 In $\mathrm{MeOH}$, the enantioselective responses are high: Z. Huang, S. S. Yu, X. Q. Yu and L. Pu, Chem. Sci., 2014, 5, 3457-3462.

10 H. Brunner and J. Goldbrunner, Chem. Ber., 1989, 122, 20052009.

11 H.-C. Zhang, W.-S. Huang and L. Pu, J. Org. Chem., 2001, 66, 481-487.

12 Z. Huang, S.-S. Yu, X. Zhao, K.-L. Wen, Y.-M. Xu, X.-Q. Yu, Y. Xu and L. Pu, Chem.-Eur. J., 2014, 20, 16458-16461. 